\title{
¿Cómo diseñar un buen proyecto STEM? Identificación de tensiones en la co-construcción de una rúbrica para su mejora
}

\author{
Miguel Pérez-Torres (D), Digna Couso iD, Conxita Márquez (D) \\ Departamento de Didáctica de la Matemática y las Ciencias experimentales. Barcelona. España. \\ miquel.perez@uab.cat,digna.couso@uab.cat,conxita.marquez@uab.cat
}

[Recibido: 27 noviembre 2019. Revisado: 23 mayo 2020. Aceptado: 6 junio 2020]

\begin{abstract}
Resumen: En un contexto donde la enseñanza de las ciencias en educación secundaria frecuentemente se realiza a través de la metodología ABP, aparece la necesidad de disponer de instrumentos que permitan mejorar la calidad de los proyectos STEM que se implementan. Con esta finalidad, y a partir de un modelo de ciencia escolar basado en participar de las formas de hacer, pensar y hablar de las ciencias este estudio se plantea en el contexto de un proceso de co-construcción y validación por expertos de una rúbrica de mejora de proyectos STEM en 3 fases. En este escenario, se desarrolla una investigación evaluativa desde una aproximación cualitativa-interpretativa analizando el discurso de los expertos pertenecientes a un grupo de investigación en didáctica. De este análisis se identificaron 4 grandes tensiones en el consenso de indicadores para establecer criterios para la mejora de los proyectos.
\end{abstract}

Palabras clave: ABP; ACE; competencia STEM; Rúbrica.

\section{Rubric co-construction for the assessment of STEM high school projects}

\begin{abstract}
Regarding the growing use of PBL for teaching and learning high school Science, there appears the necessity of instruments that make STEM projects evaluation feasible. For that purpose, based on a cognitive model of Science Education that focuses on how scientist work, think and communicate, it was developed a coconstruction and validation process of a rubric instrument. Aided by an interdisciplinary research group on Science Education, the 3-step co-construction process was the context of an evaluative investigation from a qualitative-interpretative approach. By analyzing participants discourse, 4 major tensions were found to have direct implications on project improvement.
\end{abstract}

Keywords: PBL; School Scientific Practices; STEM competence; Rubric.

Para citar este artículo: Pérez-Torres M., Couso D. y Márquez C. (2021) ¿Como diseñar un buen proyecto STEM? Identificación de tensiones en la co-construcción de una rúbrica para su mejora. Revista Eureka sobre Enseñanza y Divulgación de las Ciencias 18(1), 1301. doi: 10.25267/Rev_Eureka_ensen_divulg_cienc.2021.v18.11.1301

\section{Introducción}

A lo largo de la última década, en el ámbito educativo ha resurgido un movimiento de innovación pedagógica propulsado por las inquietudes del profesorado y centros de educación secundaria de ofrecer una enseñanza más competencial y conectada con el entorno. Este proceso ha conllevado que metodologías como el Aprendizaje Basado en Proyectos (ABP) sean frecuentes en la enseñanza-aprendizaje de las ciencias (Sanmartí y Márquez 2017; Hasni, Bousadra, Belletête, Benabdallah, Nicole y Dumais 2016).

También recientemente en nuestro país, siguiendo la tendencia internacional, la enseñanza de las ciencias se está planteando cada vez más en entornos que integran en mayor o menor medida la Ciencia, la Tecnología, la Ingeniería, y las Matemáticas, es decir, la denominada perspectiva STEM por sus siglas en inglés (Martín-Páez, Aguilera, Perales-Palacios y VílchezGonzález 2019). Esta perspectiva STEM engloba diferentes enfoques y propuestas, incluyendo variedad de herramientas tecnológicas, perspectivas pedagógicas y enfoques metodológicos

\author{
Revista Eureka sobre Enseñanza y Divulgación de las Ciencias \\ Universidad de Cádir. APAC-Eureka. ISSN: 1697-011X \\ bttp://doi.org/10.25267/Rev_Eureka_ensen_divulg_cienc.2021.v18.i1.1301 \\ bttp:/ / reuredc.uca.es
}


que se consideran adecuados para los diversos objetivos a los que se asocia la educación STEM (Couso 2017).

Integrando ambas tendencias, en los contextos de innovación educativa en educación científica vemos como parte del profesorado de ciencias se implica en el diseño e implementación de "proyectos STEM" (Doménech-Casal et al 2019), que podríamos definir como propuestas curriculares que incluyen características de la metodología ABP para la enseñanza y aprendizaje en el área científico-tecnológica. La variedad de tipologías que los autores encuentran entre los proyectos STEM diseñados por docentes en ejercicio nos muestra que, al igual que pasa con la visión de la educación STEM entre los investigadores (Martín-Páez et al, 2019), la concepción de proyecto STEM es diversa entre el profesorado de ciencias. Por consiguiente, aparece la necesidad de identificar criterios y orientaciones que permitan la selección, diseño y/o adaptación de proyectos STEM que tengan suficiente calidad didáctica, identificando de forma precisa sus potencialidades y espacios de mejora.

En este sentido se están realizando intentos de ofrecer herramientas, en particular rúbricas, que faciliten evaluar el diseño estos proyectos STEM (Domènech, Lope y Mora 2019; Capraro, Capraro y Morgan 2013, p 199). Este estudio pretende dar respuesta a parte de estas necesidades al plantear el contexto de co-construcción de una rúbrica para la mejora de proyectos STEM que: 1) señale los elementos clave en el diseño de proyectos STEM de educación secundaria y 2) que permita realizar un análisis minucioso de sus estadios de mejora a través de sus niveles.

La co-construcción de esta rúbrica se sitúa en el marco de un grupo de investigación compuesto por profesores de educación secundaria e investigadores en didáctica de las ciencias que se centran en la reflexión sobre el lenguaje y la enseñanza de las ciencias (LIEC) y que sostienen una larga tradición en desarrollar instrumentos como el que se presenta.

\section{Objetivo de la investigación}

El proceso de creación de rúbricas habitualmente conlleva un consenso de definiciones e indicadores de mejora que pocas veces se analiza o que se resuelve con estrategias como cuestionarios dicotómicos (Alsina, Ayllón y Colomer 2019). Este estudio se focaliza en comprender y hacer explícitas las formas de contrastar y construir criterios de mejora. Por ello el objetivo principal se concreta en:

Caracterizar las tensiones que emergen en un proceso de co-construcción de una rúbrica de mejora de proyectos STEM.

Considerando el contexto donde emergen dichas tensiones, se incluye como sub-objetivo de carácter metodológico la co-construcción de una rúbrica validada por expertos que permita determinar niveles de mejora para la selección, diseño y/o adaptación de proyectos STEM.

\section{Marco Teórico}

Actualmente, el ABP aplicado a la enseñanza de las ciencias, conocido también como Ciencia Basada en Proyectos (CBP) (Krajcik y Shin 2014; Hasni et al 2016), se presenta como una metodología con características propias. En su revisión de más de 45 artículos de ABP aplicado al ámbito científico-tecnológico, Hasni et al (2016) encuentran que los elementos propios de los proyectos de enseñanza de las ciencias y la tecnología son, en orden de importancia: a) un problema o pregunta científica auténtica, b) un proceso de indagación científica y/o diseño ingenieril, c) la demanda de un producto final que requiera aplicar conocimiento científico-tecnológico, d) el trabajo de forma cooperativa, y e) un uso extensivo de las TICs. 
Ante estos elementos, se plantean grandes retos en el diseño didáctico de proyectos de ámbito científico-tecnológico con enfoque ABP, tales como generar demandas que genuinamente requieran contenidos curriculares o disciplinares propios de las ciencias para el alumnado (Kanter 2010). Una propuesta interesante para combinar la metodología ABP con la construcción de conocimiento científico sería la de Krajcik y Shin (2014), que destacan la importancia de marcar unas finalidades de aprendizaje que integren la selección de ideas clave (NRC 2012) con la participación en prácticas científicas (Osborne 2014), donde cobra importancia el discurso dialógico en el aula (Alozie, Moje y Krajcik 2010). El propósito sería desplazar el énfasis, tanto en el aula tradicional como en las propuestas de ABP, de los productos de la ciencia (hechos, conceptos, leyes, etc.) hacia las prácticas de la ciencia, en concreto de modelización, indagación y argumentación (Grandy y Duschl 2012).

Esta forma de entender la enseñanza de las ciencias en el contexto metodológico ABP encaja con la visión sobre la enseñanza de las ciencias basada en la participación en la Actividad Científica Escolar (ACE) que compartimos. La ACE es una propuesta didáctica que se plantea sobre un modelo cognitivo de ciencia que entiende que la actividad científica que se debe propiciar en la escuela debe emular la actividad social, discursiva y cognitiva de los científicos, aunque sus objetivos, métodos y constructos mentales finales no sean los mismos (Izquierdo 1999). Desde esta premisa, en la perspectiva ACE la actividad en el aula de ciencias se centra en compartir una forma de hacer, pensar, hablar (y sentir) (Aliberas, Gutiérrez e Izquierdo 2019) una ciencia que cobra sentido en el contexto escolar. En la práctica, la ACE enfatiza (Izquierdo 1999):

1. enseñar en contexto, conectando con las experiencias y emociones del alumno, de forma que le permita reinterpretar fenómenos del mundo desde el conocimiento científico escolar (Espinet 2014).

2. despertar el interés por «actuan» en el mundo, participando en prácticas científicas escolares que lo modelicen y permitan la intervención intencionada en los fenómenos (observando, experimentando, argumentando, ...) y la toma de decisiones sociocientíficas de forma adecuada (Sanmartí y Márquez 2017).

3. construir con los alumnos unas «ideas clave» o Modelos Científicos Escolares (MCE) que les permitan describir, predecir e interpretar una gran variedad de fenómenos que, pese a su aparente diversidad, se explican activando un mismo MCE a un nivel más o menos sofisticado, en progresión a lo largo de la escolaridad (Couso 2014).

4. adoptar un modelo de evaluación que impulse la metacognición y la autorregulación respecto a los procesos de construcción de nuevos conocimientos, donde el aprendiz reconozca su progreso (Sanmartí 2010).

En nuestro contexto, la mirada de la ACE se ha usado para el diseño de materiales educativos desde diferentes perspectivas, influenciada por marcos como tradicionalmente el CTS y más recientemente las perspectivas SSI o STEM. Esto ha implicado ampliar la mirada a la inclusión de nuevos objetivos de aprendizaje, hablando de proyectos de ámbito científico-tecnológico que promueven no sólo actividad científica sino una actividad STEM escolar que engloba la práctica de la ingeniería y la práctica matemática de forma más o menos integrada. Estos proyectos van orientados al desarrollo de la competencia STEM, entendiendo ésta como «la capacidad de identificar y aplicar tanto los conocimientos clave como las formas de hacer, pensar, hablar y sentir de la ciencia, la ingeniería y la matemática, de forma más o menos integrada, con el fin de comprender, decidir y/o actuar delante de problemas complejos y para construir soluciones creativas e innovadoras, aprovechando las sinergias personales y las tecnologías disponibles, y de forma crítica, reflexiva y con valores» (p. 24, Couso 2017). En esta forma de entender la competencia STEM, que es análoga a la forma de entender la 
competencia científica desde la perspectiva ACE, se destaca: 1) que la interrelación de disciplinas debería respetar la forma de trabajar de cada una de ellas (naturaleza epistémica) (Couso y Simarro, 2020), y 2) que la activación de diferentes formas de trabajar se haga en función del reto competencial planteado. Esto señala la importancia de no centrar la actividad STEM escolar en el resultado final, que suele ser un producto o actuación concreto (Domènech 2018), sino en aquellas prácticas (formas científicas, matemáticas o de la ingeniería de hacer, pensar, hablar) que se movilizan y se aprenden en el desarrollo de la misma.

\section{Proceso de co-construcción y validación de una rúbrica para la mejora de proyectos STEM}

Con el fin de construir un instrumento que fomente una reflexión en profundidad sobre los proyectos STEM y que permita orientar su selección, diseño y/o mejora, se planificó un proceso de co-construcción y validación por expertos en didáctica de las ciencias y STEM de una rúbrica. Para el diseño de esta rúbrica, se tuvo en cuenta dos elementos: 1) que fuera coherente con la visión del profesorado que implementa actualmente proyectos STEM en educación secundaria y 2) que incorporara elementos clave de la perspectiva de enseñanzaaprendizaje del marco de ACE en el contexto STEM (Actividad STEM Escolar) descrito anteriormente.

Considerando estas premisas, se partió de una revisión bibliográfica de investigaciones centradas en la CBP y el STEM ABP (Krajcik y Shin 2014, Domènech, 2018) y de un estudio enfocado a la caracterización de la visión sobre proyectos STEM de 6 profesores con larga experiencia en su diseño e implementación, a partir de entrevistas en profundidad (PérezTorres 2017). Los resultados de este estudio y la revisión bibliográfica permitieron obtener unos primeros ámbitos sobre qué aspectos son clave en el diseño e implementación de proyectos STEM. Así mismo, se aportaron consideraciones concretas para la redacción de los indicadores y sus niveles que constituyeron una primera versión de la rúbrica (pre-rúbrica 1).

El proceso de co-construcción y validación por expertos se realizó en el contexto del grupo de investigación e innovación LIEC, implicado en el desarrollo operativo del marco ACE. Dicho grupo, compuesto por académicos universitarios en didáctica de las ciencias y profesores de educación secundaria, permitió constituir un panel de expertos que validaran el contenido de la rúbrica. Concretamente, el panel constaba de 20 participantes (5 docentes de secundaria, 6 investigadores y 9 con perfil mixto docente/investigador) que se definieron como expertos por: a) su experiencia de más de 10 años en la docencia de alguna de las 4 disciplinas STEM y/o b) su investigación reconocida con aportaciones en didáctica de las ciencias y/o del enfoque STEM.

Este proceso de co-construcción y validación se realizó en 3 fases (Figura 1). 


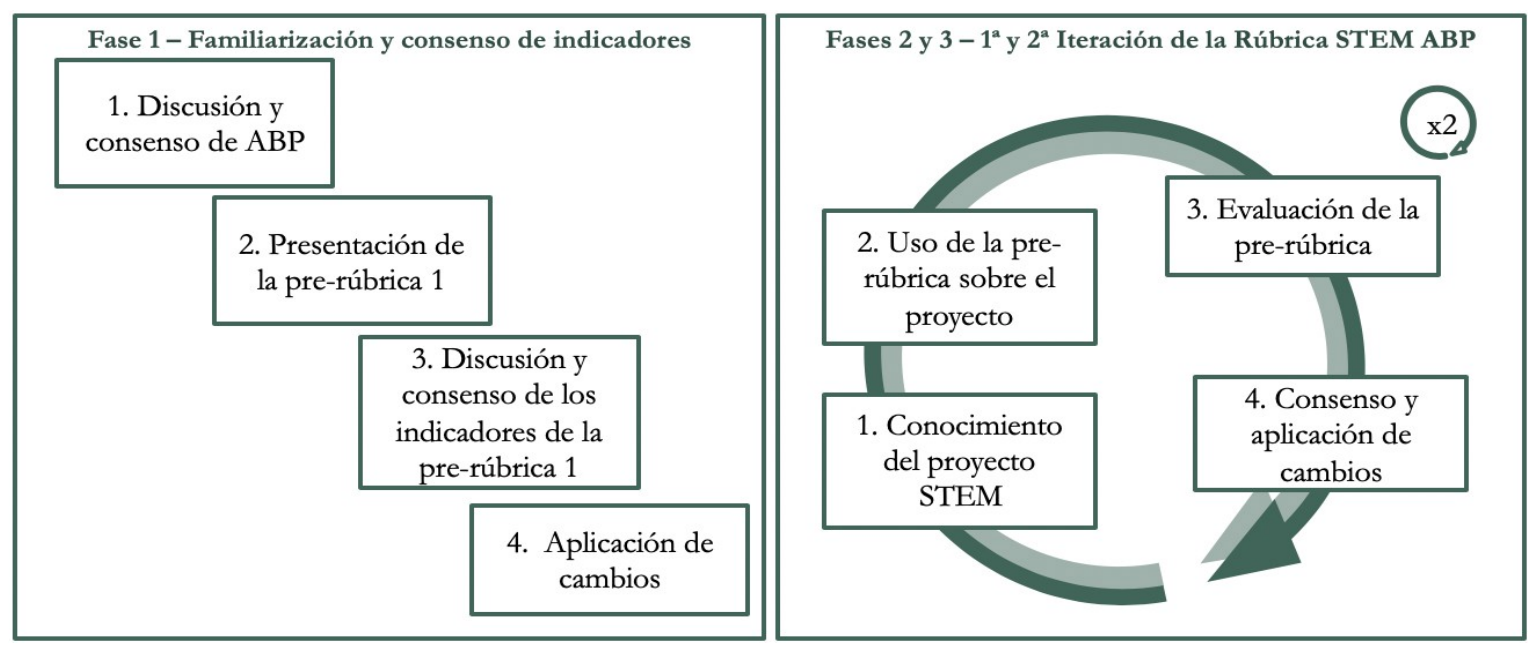

Figura 1. Representación de las 3 fases del proceso de co-construcción y validación de la rúbrica STEM ABP.

\section{Fase 1 - Familiarización y consenso de indicadores}

Esta primera fase guió el panel de expertos a través de los siguientes pasos:

1. Discusión y consenso de una definición de metodología $A B P$. Se presentó una definición teórica (Krajcik y Shin 2014; Hasni et al 2016) sobre los elementos que caracterizan la metodología (definida anteriormente) y se discutieron añadiendo y consensuando matices ante como se entienden en nuestro contexto educativo.

2. Presentación de la pre-rúbrica 1. El investigador presentó la pre-rúbrica 1 a partir de su estructura en respuesta a 3 preguntas clave: para qué, qué y cómo realizar proyectos STEM de enseñanza-aprendizaje de ciencias, que a su vez se dividía por ámbitos, indicadores y 4 niveles para cada indicador. Más concretamente, la pre-rúbrica 1 comprendía 6 ámbitos: Finalidades, Contenidos, Contexto, Acción, Prácticas Científico-Tecnológicas (CT) y Evaluación, y un total de 14 indicadores distribuidos entre estos.

3. Discusión y consenso de indicadores de la pre-rúbrica 1. Se realizó un debate sobre los ámbitos de la pre-rúbrica 1 donde se solicitaron sugerencias a distintos niveles. A través de la revisión de cada ámbito se abrieron sucesivas discusiones centradas en: 1) la adecuación de los indicadores preestablecidos para cada ámbito, 2) la co-construcción de nuevos indicadores para reflexionar sobre los proyectos STEM, y 3) la redacción de los descriptores de los niveles de resultado.

4. Aplicación de cambios. Los cambios sugeridos se añadieron a la pre-rúbrica 1 una vez completada la sesión.

Como subproducto de esta fase se obtuvo una segunda versión de la rúbrica (pre-rúbrica 2).

\section{Fases 2 y 3 - Primera y segunda iteración de la rúbrica}

En las fases 2 y 3 del proceso de co-construcción y validación se aplicaron las pre-rúbricas 2 y 3 , respectivamente, a dos proyectos STEM con el objetivo de centrar la discusión en la aplicabilidad de los indicadores sobre ejemplos concretos.

Siguiendo un ciclo de 2 iteraciones realizadas en dos sesiones distintas, para cada ciclo se realizaron las siguientes acciones:

1. Conocimiento del proyecto STEM. Ambas iteraciones comenzaron con la presentación de un proyecto STEM real, elegido siguiendo los criterios de: reconocimiento social (a través de un premio) y educativo (propuesto por algún participante del grupo XXXX) y 
accesibilidad de sus materiales didácticos. Los materiales de dichos proyectos están disponibles en:

- Proyecto Iteración 1: Natusfera Biodiversity Congress (premiado por MSchools, 2018).

- Proyecto Iteración 2: Nosotros te informamos, tu decides (escogido por los miembros del LIEC como buen ejemplo).

2. Uso de la pre-rúbrica sobre el proyecto. En la primera iteración, la pre-rúbrica 2 fue aplicada por 5 grupos de 3-4 participantes, que aplicaron conjuntamente cada indicador a partir de los descriptores de los 4 niveles de resultado (siendo el $4^{\circ}$ el de mayor sofisticación). Para facilitar la comparación entre grupos, las valoraciones de los 5 grupos se recogieron a través de un formulario digital que se representó en gráficos radiales (Figura 2.a). En la segunda iteración, de forma ya individual, se aplicó la pre-rúbrica 3 representando los resultados en otro gráfico homólogo (Figura 2.b). Durante el proceso, los participantes tuvieron acceso al material didáctico del proyecto STEM analizado en formato digital y la rúbrica en papel sobre la cual se pudieron hacer comentarios a medida que se le daba uso.

3. Evaluación de la pre-rúbrica. Durante la aplicación de la rúbrica para cada proyecto, los expertos propusieron mejoras más precisas para los descriptores de la rúbrica que se adecuaran no sólo a las reflexiones teóricas sino también a los proyectos concretos analizados. Además, se hicieron reflexiones generales a partir de los gráficos representados (Figura 2).

4. Consenso y aplicación de cambios. Una vez finalizadas ambas fases, se realizaron las modificaciones pertinentes a la rúbrica considerando las reflexiones y sugerencias de los expertos.

Después de la doble iteración realizada se obtuvo una versión final de la rúbrica que se presenta como un producto final de este proceso de co-construcción. Ésta comprende 7 ámbitos de los proyectos STEM que agrupan 21 indicadores (Tabla 1). Para cada indicador se especifican 4 niveles de resultado que proponen un orden progresivo de mejora, para los que se incluyen descriptores que ejemplifican sus características (Anexo 1).

Tabla 1. Estructura final de la rúbrica co-construida con las definiciones consensuadas de cada ámbito.

\begin{tabular}{|c|c|c|c|}
\hline \multicolumn{4}{|c|}{ Estructura de la Rúbrica STEM ABP construida } \\
\hline Pregunta clave & Ámbito & Definición del ámbito & Indicadores \\
\hline \multirow{3}{*}{ ¿Para qué? } & \multirow{3}{*}{ Finalidades } & \multirow{3}{*}{$\begin{array}{l}\text { Conjunto de propósitos que promueven } \\
\text { la realización del proyecto que incluyen } \\
\text { los objetivos curriculares, los objetivos } \\
\text { didácticos y el objetivo asociado a la } \\
\text { acción del proyecto. }\end{array}$} & Finalidades de aprendizaje \\
\hline & & & Finalidades didácticas \\
\hline & & & Reto del proyecto \\
\hline \multirow{7}{*}{ ¿Qué? } & \multirow{4}{*}{ Contenidos } & \multirow{4}{*}{$\begin{array}{l}\text { Conjunto de conocimientos (teóricos y } \\
\text { prácticos) y actitudes seleccionados, así } \\
\text { como las formas de organizarlos e } \\
\text { integrarlos en el proyecto. }\end{array}$} & $\begin{array}{l}\text { Selección y profundidad de } \\
\text { contenidos teóricos }\end{array}$ \\
\hline & & & $\begin{array}{l}\text { Selección y profundidad de } \\
\text { contenidos procedimental- } \\
\text { epistémicos }\end{array}$ \\
\hline & & & $\begin{array}{l}\text { Selección y profundidad de } \\
\text { contenidos actitudinales y valores }\end{array}$ \\
\hline & & & $\begin{array}{l}\text { Integración de conocimientos } \\
\text { entre asignaturas }\end{array}$ \\
\hline & \multirow{3}{*}{ Acción } & \multirow{3}{*}{$\begin{array}{l}\text { Producto o toma de decisión que se } \\
\text { genera en respuesta a la pregunta o reto } \\
\text { que plantea un proyecto. }\end{array}$} & Despliegue de la acción \\
\hline & & & $\begin{array}{l}\text { Ámbito de realización e impacto } \\
\text { social }\end{array}$ \\
\hline & & & Obertura del producto \\
\hline
\end{tabular}


Tabla 1. Continuación

\begin{tabular}{|c|c|c|c|}
\hline \multicolumn{4}{|c|}{ Estructura de la Rúbrica STEM ABP construida } \\
\hline $\begin{array}{l}\text { Pregunta } \\
\text { clave }\end{array}$ & Ámbito & Definición del ámbito & Indicadores \\
\hline \multirow{11}{*}{ ¿Cómo? } & \multirow{5}{*}{$\begin{array}{l}\text { Prácticas } \\
\text { Científico- } \\
\text { Tecnológicas }\end{array}$} & \multirow{5}{*}{$\begin{array}{l}\text { Conjunto de las formas de pensar, hacer } \\
\text { y comunicar de la ciencia y la tecnología } \\
\text { escolar que se fomentan en el proyecto. }\end{array}$} & Argumentación \\
\hline & & & Indagación \\
\hline & & & Modelización \\
\hline & & & Prácticas ingenieras \\
\hline & & & Uso de recursos TIC \\
\hline & \multirow{3}{*}{ Contexto } & \multirow{3}{*}{$\begin{array}{l}\text { Hilo conductor que da sentido al } \\
\text { reto/pregunta que plantea el proyecto, } \\
\text { así como los contenidos y prácticas que } \\
\text { se desarrollan. }\end{array}$} & Relevancia \\
\hline & & & Significatividad Científica \\
\hline & & & Autenticidad \\
\hline & \multirow{2}{*}{ Evaluación } & \multirow{2}{*}{$\begin{array}{l}\text { Mecanismos de regulación que se usan } \\
\text { para guiar tanto el aprendizaje como la } \\
\text { realización de la acción. }\end{array}$} & Evaluación del proceso \\
\hline & & & Evaluación del resultado \\
\hline & Cooperación & $\begin{array}{l}\text { Mecanismos de regulación del trabajo en } \\
\text { grupo. }\end{array}$ & $\begin{array}{l}\text { Regulación del trabajo } \\
\text { cooperativo }\end{array}$ \\
\hline
\end{tabular}

\section{Metodología}

Desde la perspectiva de la investigación evaluativa, se usó un enfoque interpretativo para analizar los datos y realizar un análisis del discurso de los participantes. Esta metodología evaluativa se considera adecuada para este estudio porque permite analizar la orientación del cambio y la toma de decisiones y adaptar el proceso de investigación a las necesidades del contexto (Rossi y Freeman 1993).

La estrategia de recogida de datos incluyó grabaciones en audio de las discusiones y aportaciones de los expertos del grupo LIEC, las actas de las reuniones y las producciones de los expertos durante las sesiones de las fases 1, 2 y 3 presentadas.

A partir de un proceso de inducción-deducción, las aportaciones de los participantes, grabadas en audio, se segmentaron de acuerdo con los indicadores de la rúbrica presentes en la discusión. Posteriormente, se identificaron las relaciones que se daban entre los indicadores y se seleccionaron aquellas que manifestaban dificultad en obtener niveles de resultados altos en dos indicadores simultáneamente. Éstas se categorizaron y reagruparon dando lugar a la identificación de 4 tensiones principales.

Tomando como ejemplo la cita 1 del participante L: "a veces buscas contextos que estimulen lo suficiente para poder explicar lo que quieras y no tan perfectamente diseñados para poder trabajar el modelo", se identifican 2 indicadores asociados al contexto:

- Cita 1.a. "contextos que estimulen lo suficiente para poder explicar lo que quieras" hace referencia a la relevancia del contexto (contextos suficientemente relevantes para el alumno como para mantener su atención).

- Cita 1.b "[contexto] perfectamente diseñado para poder trabajar el modelo" - hace referencia a la significatividad del contexto (contextos suficientemente significativos para la ciencia escolar que permitan reinterpretar fenómenos con modelos científicos escolares más sofisticados).

A partir de la cita 1, también se categorizaron dos relaciones entre la relevancia y la significatividad de contexto: 
- En la cita 1.a, se interpreta que hay una relación positiva entre contextos «que estimulen» (que sean relevantes) y poder proponer actividades que involucren a los alumnos en trabajar otros contenidos «explicar lo que quieras».

- Entre las citas 1.a y 1.b, por otro lado, se interpreta que hay una relación negativa (tensión) entre este contexto «que estimule» y el contexto que permite «trabajar un modelo». Esta cita 1.b matiza la relación positiva manifestada en la cita 1.a, entendiéndose que un contexto relevante «que estimule» permite incluir ciertas «explicaciones» puntuales pero que entra en tensión cuando hay que «trabajar un modelo» de forma prolongada (el contexto no facilita reinterpretar/modelizar fenómenos, es decir, no es un contexto altamente significativo).

Esta dificultad de usar contextos que permitan a la vez mantener la relevancia (personal, social o profesional) del alumnado y que permitan ser reinterpretados científicamente se categorizó como una tensión implícita entre estos indicadores. Este proceso de análisis se realizó con el software Atlas.ti (v8).

\section{Resultados y Discusión}

Los resultados de esta investigación evaluativa se estructuran en la identificación de 4 tensiones respecto los indicadores y niveles de la rúbrica.

\section{Tensiones principales en el consenso de indicadores: ¿Qué aspectos son importantes tener en cuenta al seleccionar, diseñar o adaptar un proyecto STEM?}

Durante la discusión en las fases de co-construcción y validación de la rúbrica, se pudieron identificar 4 tensiones principales relacionadas con algunos indicadores que se propusieron en la rúbrica. A continuación, se presentan y discuten estas tensiones y cómo se ponen de manifiesto a través de los distintos niveles de progresión en la rúbrica.

\section{a) Tensión 1 entre seleccionar y construir ideas clave (modelizar) y desarrollar una acción con impacto social.}

En la Fase 1 (consenso de indicadores) y en la Fase 2 ( $1^{\text {a }}$ iteración) de esta co-construcción se hacen valoraciones, tanto generales como en relación al proyecto analizado, que ponen en cuestión la posibilidad de diseñar proyectos STEM que sirvan para construir ideas en profundidad (que modelicen a nivel 3 o 4) y a la vez alcancen niveles altos de los indicadores asociados al ámbito de acción (que implican poner en práctica y evaluar una acción real, y que repercuta a un público externo). Así aparecen opiniones como la del participante E que pone en valor proyectos con menor impacto social pero que profundizan en aquellas competencias que se desean desarrollar en el alumnado: «tal vez lo hacemos muy bien [construir ideas clave], y hemos de valorar que está muy bien hecho, pero, a cambio, nos hemos quedado en el aula...» A parte de los indicadores de la rúbrica mencionados, esta tensión se aprecia en la progresión de niveles del indicador Reto del proyecto, que evoluciona desde proyectos que proponen retos con tareas reproductivas, a retos más sofisticados que implican comprender en profundidad una situación para tomar decisiones (Tabla 2), donde esta tensión entre acción y modelización se hace más intensa. 
Tabla 2. Apartado de la rúbrica relacionado con el Reto del Proyecto.

\begin{tabular}{|c|c|c|c|c|}
\hline Indicador & Nivel 1 & Nivel 2 & Nivel 3 & Nivel 4 \\
\hline $\begin{array}{l}\text { Reto del } \\
\text { proyecto }\end{array}$ & $\begin{array}{l}\text { El reto/pregunta } \\
\text { guía plantea } \\
\text { tareas } \\
\text { reproductivas. } \\
\text { Aparecen pocas } \\
\text { restricciones que } \\
\text { impliquen la } \\
\text { necesidad de } \\
\text { comprender r } \\
\text { alguna situación. }\end{array}$ & $\begin{array}{l}\text { Se plantea un } \\
\text { reto/pregunta } \\
\text { provocativos, que } \\
\text { se resuelve a largo } \\
\text { plazo y que se } \\
\text { puede realizar sin } \\
\text { una necesidad clara } \\
\text { de responder a un } \\
\text { objetivo } \\
\text { aprendizaje. }\end{array}$ & $\begin{array}{lr}\text { Se plantea un } \\
\text { reto/pregunta } \\
\text { provocativos, } \\
\text { apropiado en dificultad } \\
\text { y que se resuelve a } \\
\text { largo plazo. Aparecen } \\
\text { restricciones } & \text { que } \\
\text { responden a } & \text { algún } \\
\text { objetivo } & \text { de } \\
\text { aprendizaje. } & \end{array}$ & $\begin{array}{l}\text { Se plantea un reto/pregunta } \\
\text { provocativos, apropiado en } \\
\text { dificultad y que se resuelve a } \\
\text { largo plazo. Implica analizar } \\
\text { y comprender una situación } \\
\text { para poder valorar y } \\
\text { argumentar la toma de } \\
\text { decisiones (acción), que } \\
\text { responden a varios } \\
\text { objetivos de aprendizaje } \\
\text { marcados. }\end{array}$ \\
\hline
\end{tabular}

b) Tensión 2 entre desarrollar contenidos de diferentes asignaturas de forma integrada y hacerlo en profundidad.

Otra de las tensiones que aparecen en el análisis de las discusiones trata la dificultad de integrar conocimientos de distintas asignaturas, con diferentes intereses y objetivos, en un mismo proyecto. Aunque en ambos proyectos presentados las ciencias toman el papel protagonista, los participantes hicieron valoraciones que ponen de manifiesto la dificultad de profundizar en ciertos contenidos respetando las constricciones que generan otras asignaturas presentes en el proyecto. Por ejemplo, dos participantes ( $\mathrm{C}$ y $\mathrm{D}$ ) comentaron su experiencia sobre la participación en el diseño de un proyecto entendido como STEAM (incluyendo al enfoque STEM la A de Arte) donde la discusión sobre cómo trabajar el concepto de evolución se veía limitada por la asignatura de artes plásticas, mencionando que «pierdes un poco el fenómeno que quieres estudiar». Esta tensión se recoge en el indicador de Integración de conocimientos entre asignaturas de la rúbrica (Tabla 3), donde, a través de sus niveles de progresión, se valora más la calidad de las conexiones entre las asignaturas (aunque sean menos) que la cantidad. Cabe destacar la importancia de esta discusión en el ámbito STEM, donde frecuentemente se prioriza la integración de disciplinas frente la profundidad en cada una (Couso y Simarro 2020).

Tabla 3. Apartado de la rúbrica relacionado con la Integración de contenidos entre asignaturas.

\begin{tabular}{|c|c|c|c|c|}
\hline Indicador & Nivel 1 & Nivel 2 & Nivel 3 & Nivel 4 \\
\hline $\begin{array}{l}\text { Integración de } \\
\text { contenidos entre } \\
\text { asignaturas }\end{array}$ & $\begin{array}{l}\text { Se trabajan y } \\
\text { relacionan } \\
\text { ideas } \\
\text { cotidianas } \\
\text { sobre el tema } \\
\text { tratado o re } \\
\text { trabaja una } \\
\text { única } \\
\text { asignatura. }\end{array}$ & $\begin{array}{l}\text { El contenido de } \\
\text { diferentes } \\
\text { asignaturas } \\
\text { trabaja se } \\
\text { separado por } \\
\text { hacen } \\
\text { aportaciones } \\
\text { independientes } \\
\text { en el proyecto. }\end{array}$ & $\begin{array}{l}\text { Los contenidos de } \\
\text { diferentes asignaturas } \\
\text { se trabajan por } \\
\text { separado, pero se usan } \\
\text { de forma convergente } \\
\text { en la producción final. } \\
\text { Puede aparecer una } \\
\text { asignatura central y } \\
\text { otras que hagan } \\
\text { aportaciones. }\end{array}$ & $\begin{array}{l}\text { Los contenidos de diferentes } \\
\text { asignaturas se integran y } \\
\text { contrastan durante todo el } \\
\text { proyecto. El proyecto supone } \\
\text { trabajar simultáneamente con } \\
\text { las aportaciones que puede } \\
\text { hacer cada una. Suelen } \\
\text { integrarse } 2 \text { o } 3 \text { asignaturas } \\
\text { con un peso similar en el } \\
\text { proyecto. }\end{array}$ \\
\hline
\end{tabular}

c) Tensión 3 entre la selección de contextos relevantes para el alumnado y contextos significativos para aprender ciencia.

En la discusión de la Fase 1 sobre cómo se entienden los términos de relevancia y significatividad de forma general al hablar del contexto, y la forma de usar estos términos durante toda la construcción de la rúbrica, resalta una tercera tensión implícita entre estos términos. Al definir el contexto en términos de: a) relevancia (considerada como la conexión 
del contexto con las experiencias, intereses, etc. de los aprendices) y b) significatividad (considerada como la capacidad de albergar fenómenos investigables que permitan nuevas formas de ver el mundo), aparece implícita la tensión entre los intereses del alumno y los intereses de la ciencia escolar. Esta tensión se aprecia en comentarios como el del profesor L que pone en valoración usar «contextos que estimulen lo suficiente para poder explicar lo que quieras [relevante para el alumno] y no tan perfectamente diseñado para poder trabajar el modelo [significativo para la ciencia]».

A pesar de los esfuerzos en definir estos conceptos (Stuckey 2013), éstos suelen presentarse parcialmente superpuestos, y siguen siendo el eje de discusión de investigaciones actuales (Moraga, Espinet y Merino 2018). En concreto, cabe mencionar la revisión realizada por Kapon, Antti y Levrini (2018) que, explorando la tensión entre autenticidad disciplinar y relevancia personal, utilizan el término significatividad definido como «la negociación entre la necesidad de que el contenido y la naturaleza de las actividades sean significativos desde la perspectiva de la ciencia escolar, y que, a su vez, sean personalmente relevantes y significativas para los estudiantes» (p. 1085).

Esta tensión presentada se aprecia en gran medida en los niveles superiores de los indicadores de Relevancia y Significatividad científica en la rúbrica (Tabla 4), donde contextos muy significativos para la ciencia (que planteen preguntas investigables científicamente) pueden entrar en conflicto con contextos muy relevantes personal y socialmente (que conecten con intereses sostenidos a nivel global, individual o profesional).

Tabla 4. Apartado de la rúbrica relacionado con la Relevancia y Significatividad científica.

\begin{tabular}{|c|l|}
\hline \multicolumn{1}{|c|}{ Indicador } & \multicolumn{1}{|c|}{ Nivel 4} \\
\hline Relevancia & $\begin{array}{l}\text { Se planean situaciones y retos que conectan yenerar intereses } \\
\text { (sostenidos en el tiempo) a los alumnos a nivel: individual } \\
\text { (trabajando habilidades para su día a día), social (preparando } \\
\text { par interaccionar en sociedad) i/o profesional (ofreciendo } \\
\text { orientación). Se intenta que estas situaciones generen nuevos } \\
\text { intereses e inquietudes más allá del ámbito cotidiano. }\end{array}$ \\
\hline Significatividad científica & $\begin{array}{l}\text { Se utiliza un contexto que permite hacerse preguntas } \\
\text { investigables científicamente. Se reinterpretan fenómenos } \\
\text { incorporando nuevas formas de mirarlos (desde diferentes } \\
\text { disciplinas). El contexto da sentido a los nuevos conceptos que } \\
\text { se asocian a un nuevo lenguaje. Ofrece una imagen de cómo es } \\
\text { la actividad científica. }\end{array}$ \\
\hline
\end{tabular}

d) Tensión 4 entre desarrollar competencias cientificas clave y obtener evidencias de aprendizaje

En la discusión sobre el proyecto 1 (Fase 2) surgió una cuarta tensión entre la forma de trabajar la competencia científica (los nuevos contenidos curriculares) y la forma de evaluarla en proyectos STEM. La falta de estrategias claras que documenten y recojan pruebas del aprendizaje más allá del producto final (y/o subproductos parciales), ponen en evidencia la dificultad de evaluar el nivel de competencia alcanzado al finalizar un proyecto. Así mismo, en la evaluación de este proceso de aprendizaje, aparecen dificultades en hallar espacios de regulación que permitan reflexionar sobre el desarrollo de la competencia científica y el desarrollo del proyecto (sus etapas, productos parciales, etc) de forma paralela. Esta situación se ve reflejada en el diálogo de los participantes al no encontrar herramientas que permitan evaluar la competencia científica de forma específica y que acaben valorando otros elementos como el grado de implicación en el proyecto. Esta tensión se refleja en los niveles superiores de los indicadores relativos al ámbito de Evaluación, que resaltan la importancia de conectar el 
conjunto de objetivos de aprendizaje con las tareas que se realizan durante el proyecto, tanto en la evaluación del resultado como del proceso. (Tabla 5).

Tabla 5. Apartado de la rúbrica relacionado con la Evaluación del proceso y del resultado.

\begin{tabular}{|c|l|}
\hline \multicolumn{1}{|c|}{ Indicador } & \multicolumn{1}{|c|}{ Nivel 4} \\
\hline Evaluación del proceso & $\begin{array}{l}\text { Se discute con el alumnado los objetivos del proyecto a medida } \\
\text { que les pueden aparecer, cómo planificar la realización de } \\
\text { algunas tareas clave (transferibles), así como los criterios para } \\
\text { evaluar su calidad. Se prevé un tiempo para aplicar dichos } \\
\text { criterios a la co- y autoevaluación, vista como regulación de las } \\
\text { dificultades que vayan emergiendo. }\end{array}$ \\
\hline Evaluación del resultado & $\begin{array}{l}\text { A partir de los objetivos competenciales del proyecto, se } \\
\text { consensúan unos criterios o rúbricas y se promueve que el } \\
\text { alumnado encuentre evidencias de su trabajo que posibilite } \\
\text { deducir el nivel alcanzado. Se triangulan los puntos de vista y, } \\
\text { respecto al producto final, se valora especialmente la reflexión } \\
\text { crítica sobre qué se podría mejorar. Se evalúa considerando las } \\
\text { competencias específicas y transversales del currículo. }\end{array}$ \\
\hline
\end{tabular}

\section{La tensión entre un buen proyecto escolar y un buen proyecto STEM}

Estas 4 tensiones presentadas se pueden entender como parte de una gran tensión entre aquello que hace que el proyecto STEM siga las características asociadas al ABP (p.ej centrarse en el reto o demanda de un producto final) y aquello que hace que el proyecto STEM promueva realmente actividad STEM escolar (p. ej. que trabaje contenidos STEM y que se participe en prácticas STEM). Aunque no siempre se manifieste, esta tensión aparece implícita en múltiples estudios, al resaltar la importancia de incluir y considerar contenidos centrales del currículo como elementos caracterizadores de proyectos STEM (Krajcik y Shin 2014). En revisiones sobre qué justificaciones se usan para promover el STEM ABP también aparece esta tensión, que se discute en términos de finalidades de aprendizaje específicas de las disciplinas STEM (objetivos de aprendizaje específicos) y finalidades de aprendizaje de carácter más transversal (objetivos meta-disciplinares), como el pensamiento crítico o la creatividad (Capraro, Capraro y Morgan 2013), así como la importancia de conectar con el mundo real o aumentar la motivación (Hasni et al 2016).

En la primera tensión presentada, al considerar indicadores que evalúen una acción con un cierto despliegue o impacto social, se priorizan objetivos meta-disciplinares; mientras que, si pensamos en la profundidad con la que se podrán explorar los contenidos, pensamos principalmente en objetivos de aprendizaje específicos. Lo mismo ocurre con la tensión 2 entre abordar retos complejos integrando diversas asignaturas y, de nuevo, profundizar en contenidos concretos de una asignatura específica. En el caso de la tensión 3, analizar la calidad del contexto por su relevancia incidiría principalmente en los objetivos metadisciplinares del proyecto, mientras que la significatividad científica incidiría en los objetivos de aprendizaje específicos. Finalmente, en la tensión 4, las evidencias de la evaluación pueden centrarse en la revisión y regulación de cómo se da respuesta al reto planteado, o pueden incidir en la revisión y evaluación del desarrollo de la competencia STEM. Ambas resultan necesarias e incluso convergentes en ciertos momentos, aunque, de nuevo, respondan a objetivos diferentes.

Tomando el ejemplo de Domènech-Casal, Couso, Pérez-Torres y Márquez (2018), un proyecto con la acción de proponer soluciones para evitar el despilfarro de alimentos podría decantarse tanto a unos objetivos u otros según su diseño. Si el énfasis recae en preparar una campaña de 
sensibilización, el proyecto se puede centrar en trabajar sobre una situación de calado social, incluyendo justificaciones no sólo científicas, sino económicas, sociales, etc y destacando la calidad del producto final sobre la del proceso. En este caso priman los objetivos metadisciplinares. En cambio, si el énfasis recae en hacer propuestas de conservación de alimentos mediante la construcción de explicaciones científicas, en el proyecto probablemente habrá una asignatura guía y se centrará en construir modelos científicos escolares, como el cambio químico, a partir de contextos que lo permitan. Por lo tanto, es probable que se vigile más la calidad del proceso de construcción de propuestas (en base a estos modelos) que no su presentación final. En este segundo caso priman los objetivos específicos de aprendizaje.

En esta investigación, hemos usado esta distinción de objetivos para dividir los indicadores de la rúbrica entre aquellos que se relacionan con la consecución de los objetivos de aprendizaje específicos y aquellos indicadores que contribuyen a la consecución de objetivos metadisciplinares, que generalmente se desarrollan en contextos de ABP. En los gráficos de la Figura 2, los primeros se indican en color azul y los segundos en verde, permitiendo identificar perfiles de proyectos según qué finalidades prioricen.

\section{Perfil del Proyecto 1}

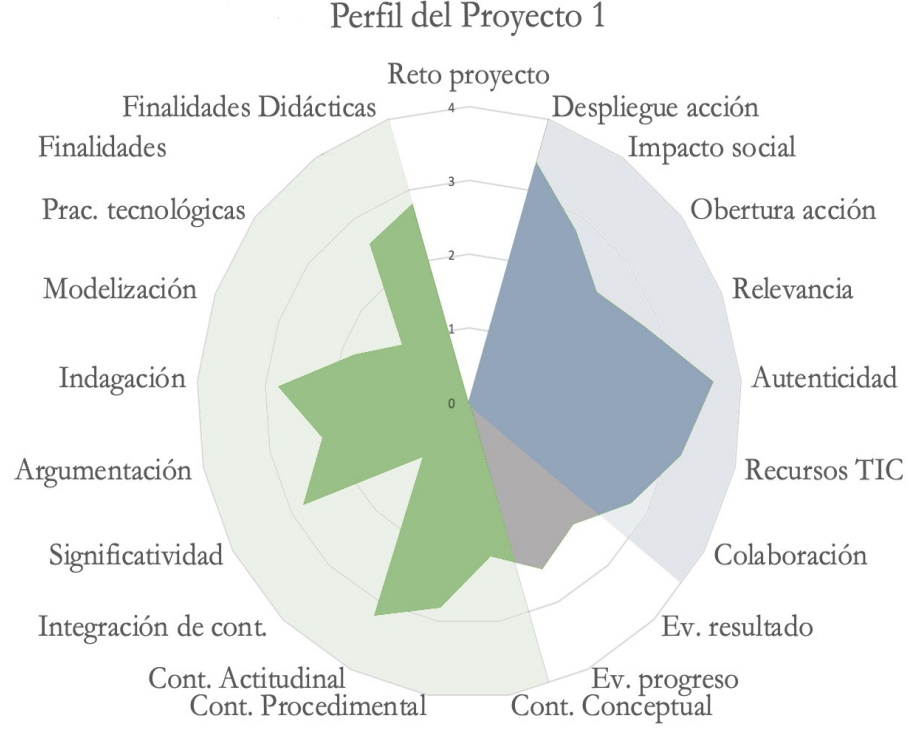

Perfil del Proyecto 2

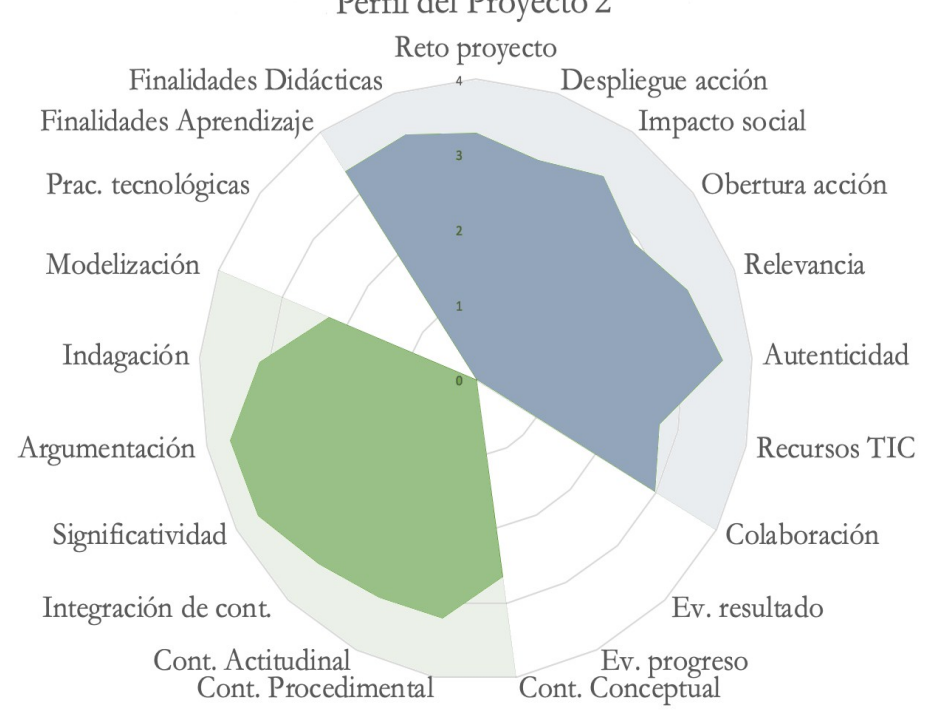

Figura 2 a y b. Representación de la aplicación de la rúbrica a los proyectos 1 y 2. Los elementos sin color no fueron valorados o responden a ambos objetivos. 
Observando los perfiles de valoración de los proyectos (Figura 2), se aprecia como el Proyecto 1 responde mejor a los objetivos meta-disciplinares y, en particular, a la acción propuesta a los alumnos (destacando a niveles altos en la mayoría de los indicadores referidos a éstos) que a los objetivos de aprendizaje específicos (donde indicadores como la Integración de contenidos, la Modelización o la Selección y profundidad de contenidos conceptuales se asocian a niveles bajos). Por otro lado, el Proyecto 2 presenta un perfil mucho más equilibrado entre los objetivos meta-disciplinares y de aprendizaje específicos.

A parte de esta visión global de los proyectos, los resultados también muestran datos interesantes sobre qué aspectos resaltan en niveles superiores e inferiores. Por ejemplo, ambos proyectos adquieren una puntuación alta en alguno de los ámbitos de la práctica científica (ya sea la argumentación o la indagación), aunque no sucede con la modelización. Así mismo, en la dimensión de los contenidos de ambos proyectos, el indicador de "Selección y profundidad de contenidos conceptuales" se valora a niveles inferiores que el resto. El hecho de que haya una puntuación baja en estos indicadores que se dirigen directamente a qué contenidos desarrollar y cómo construirlos plantea retos sobre cómo promover estos procesos de construcción a niveles sofisticados en un proyecto, y muestran la dificultad de diseñar proyectos STEM de aula desde la perspectiva ACE.

\section{Conclusiones y limitaciones}

A partir de los resultados de este estudio se hace explícita una tensión global en los proyectos STEM, que han de responder tanto a objetivos de aprendizaje específicos como a objetivos meta-disciplinares del proyecto. La caracterización de esta tensión global a través de 4 tensiones concretas permite realizar una reflexión sobre qué aspectos del diseño del proyecto responden a un objetivo u otro y realizar mejoras en él de forma más focalizada. Esta distinción permite representar unos primeros perfiles de los proyectos según el tipo de objetivo al que da mejor respuesta.

En el contexto de esta investigación, se co-construyó una rúbrica para la mejora de proyectos STEM de educación secundaria validada por expertos y que permite facilitar la selección, el diseño y/o adaptación de proyectos STEM. No obstante, se identificaron 2 limitaciones principales al usarla. Por un lado, y pese al esfuerzo prolongado de consensuar con 20 expertos los significados de cada indicador, la forma de aplicarlos sobre los proyectos se ve afectada por las formas propias de entender cada indicador. Por otro lado, en algunos casos, la forma de documentar los proyectos STEM (su diseño didáctico) puede dificultar a personas no familiarizadas con el proyecto la aplicación de ciertos indicadores de la rúbrica.

Con perspectivas de la aplicación de esta rúbrica, se abren nuevas posibilidades de investigación como la caracterización de perfiles de proyectos desde la perspectiva ACE. Actualmente, se están analizando 49 proyectos STEM que permitan caracterizar tipologías de proyectos que se implementan en las aulas.

\section{Agradecimientos}

Agradecimiento al grupo de investigación LIEC (2017SGR1399) por colaborar en esta investigación financiada por el Ministerio de Economía y Competitividad (EDU2015-66643-C2-1 y PGC2018-096581-B-C21) a través del apoyo FPI (BES-2016-078747).

\section{Referencias}

Aliberas, J., Gutiérrez, R., Izquierdo, M. (2019) Identifying Changes in a Student's Mental Models and Stimulating Intrinsic Motivation for Learning During a Dialogue Regulated 
by the Teachback Technique: a Case Study. Research in Science Education, (online), 1-29. https://doi.org/10.1007/s11165-018-9810-z

Alozie, M., Moje, E. B., Krajcik, J. (2010). An analysis of the supports and constraints for scientific discussion in high school project-based science. Science Education, 94 (3), 395427. https://doi.org/10.1002/sce.20365

Alsina, A., Ayllón, S., Colomer, J. (2019) Validating the Narrative Reflection Assessment Rubric (NARRA) for reflective narratives in higher education, Assessment $\mathrm{Y}$ Evaluation in Higher Education, 44:1, 155-168. https://doi.org/10.1080/02602938.2018.1486391

Caamaño, A. (2002). Presencia de CTS en el currículo español. P. Membiela (Ed.), Enseñanz̧a de las Ciencias desde la perspectiva Ciencia-Tecnología-Sociedad (pp. 121-133). Madrid: Narcea ediciones.

Capraro, R. M., Capraro, M. M., y Morgan, J. R. (Eds.). (2013). STEM project-based learning: An integrated science, technology, engineering, and mathematics (STEM) approach. Springer Science.

Couso, D. (2014). De la moda de "aprender indagando" a la indagación para modelizar: una reflexión crítica. Conferència Inaugural. 26 Encuentros de Didáctica de las Ciencias Experimentales. Huelva (España). Acsesible en: http://uhu.es/26edce/actas/docs/conferencias/pdf/26ENCUENTRO_DCEConferenciaPlenariaInaugural.pdf

Couso, D. (2017). Per a què estem a STEM? Un intent de definir l'alfabetització STEM per a tothom i amb valors. Ciències, 34, 22-30. https://doi.org/10.5565/rev/ciencies.403

Couso, D., Simarro, C. (2020). STEM education through the epistemological lens. In C. Johnson, M. Mohr-Schroeder, Y T. Moore (Eds.), Handbook of Research on STEM Education.

Domènech-Casal, J. (2018). Aprendizaje Basado en Proyectos en el marco STEM. Componentes didácticas para la Competencia Científica. Ápice, 2(2), 29-42. https://www.doi.org/10.17979/arec.2018.2.2.4524

Domènech-Casal, C., Couso, D., Pérez-Torres, M., Márquez, C. (2018) Propósito, Contexto y Contenido. Notas para el Aprendizaje Basado en Proyectos en Ciencias. Revista Pátio Ensino Medio, Profissional e Tecnológico, 38. 10-13.

Domènech-Casal J., Lope S., Mora L. (2019) Qué proyectos STEM diseña y qué dificultades expresa el profesorado de secundaria sobre Aprendizaje Basado en Proyectos. Revista Eureka sobre Enseñanza y Divulgación de las Ciencias 16(2), 2203. https://doi.org/10.25267/Rev_Eureka_ensen_divulg_cienc.2019.v16.i2.2203

Duschl, R. A., Grandy, R. (2013) Two Views About Explicitly Teaching Nature of Science. Science and Education, 22(9), 2109-2139. https://doi.org/10.1007/s11191-012-9539-4

Espinet, M. (2014) Perspectives sobre el context en educació científica: aproximacions teòriques i implicacions per a la pràctica educativa. Seminario de doctorado, Cerdanyola del Vallès. Accesible en: https://ddd.uab.cat/record/132369

Hasni, A., Bousadra, F., Belletête, V., Benabdallah, A., Nicole, M. C., Dumais, N. (2016) Trends in research on project-based science and technology teaching and learning at K-12 levels: a systematic review. Studies in Science Education, 52(2), 199-231. https://doi.org/10.1080/03057267.2016.1226573 
Izquierdo, M., Espinet, M., García, M.P., Pujol, R., Puig, N. (1999). Caracterización y fundamentación de la ciencia escolar. Enseñanza de Las Ciencias. no extra, 79-91.

Kanter, E. (2010) Doing the project and learning the content: Designing project-based science curricula for meaningful understanding. Science Education, 94(3), 525-551. https://doi.org/10.1002/sce.20381

Kapon, S., Laherto, A., Y Levrini, O. (2018). Disciplinary authenticity and personal relevance in school science. Science Education, 102(5), 1077-1106. https://doi.org/10.1002/sce.21458

Krajcik, J., Shin, N. (2014) Project-Based Learning. En R. Sawyer (Ed.), The Cambridge Handbook of the Learning Sciences (Cambridge Handbooks in Psychology, pp. 275-297). Cambridge University Press. https://doi.org/10.1017/CBO9781139519526.018

Martín-Páez, T., Aguilera, D., Perales-Palacios, F. J., Vílchez-González, J. M. (2019). What are we talking about when we talk about STEM education? A review of literature. Science Education, 103(4), 799-822. https://doi.org/10.1002/sce.21522

Moraga, S., Espinet, M., Merino, C. (2018) El contexto en la enseñanza de la química: Análisis de secuencias de enseñanza y aprendizaje diseñadas por profesores de ciencias en formación inicial. Revista Eureka sobre Enseñanza y Divulgación de las Ciencias, 1(1), 1604. https://doi.org/10.25267/Rev_Eureka_ensen_divulg_cienc.2019.v16.11.1604

National Research Council (2012) A Framework for K-12 Science Education: Practices, Crosscutting Concepts, and Core Ideas. Washington, DC: The National Academies Press.

OECD (2016) PISA 2015 Assessment and Analytical Framework: Science, Reading, Mathematic and Financial Literacy. PISA, OECD Publishing, Paris.

Osborne, J. (2014) Teaching Scientific Practices: Meeting the Challenge of Change. Journal of Science Teacher Education, 25(2), 177-196. https://doi.org/10.1007/s10972-014-9384-1

Pérez-Torres, M. (2017). Caracterización de proyectos cientifico-tecnológicos en educación secundaria. UAB, Bellaterra, Barcelona.

Rossi, H., Freeman, H. (1993) Evaluation: A systematic approach (5th ed.). Thousand Oaks, US: Sage Publications, Inc.

Sanmartí, N. (2010) Avaluar per aprendre. L'avaluació per millorar els aprenentatges de l'alumnat en el marc del currículum per competències , Dept. d'Educació, Generalitat de Catalunya, Barcelona. Accesible en: http://xtec.gencat.cat/web/.content/alfresco/d/d/workspace/SpacesStore/0024/fc5 3024f-626e-423b-877a-932148c56075/avaluar_per_aprendre.pdf

Sanmartí, N., Márquez, C. (2017) Aprendizaje de las ciencias basado en proyectos: del contexto a la acción. Ápice, 1(1), 3. https://doi.org/10.17979/arec.2017.1.1.2020

Stuckey M., Hofstein A., Mamlok R., Eilks I. (2013) The meaning of 'relevance' in science education and its implications for the science curriculum, Studies in Science Education, 49 (1), 1-34. 


\section{Anexo 1. Rúbrica stem abp para el análisis de proyectos stem de educación secundaria}

\begin{tabular}{|c|c|c|c|c|c|}
\hline \multirow{2}{*}{ Dim. } & \multirow{2}{*}{$\begin{array}{l}\text { Criterio de } \\
\text { Realización }\end{array}$} & \multicolumn{4}{|l|}{ Criterio de Resultado } \\
\hline & & Nivel 1 (básico) & Nivel 2 & Nivel 3 & Nivel 4 (sofisticado) \\
\hline \multirow[t]{3}{*}{ 至 } & $\begin{array}{l}\text { Finalidades de } \\
\text { aprendizaje } \\
\text { (curriculares) }\end{array}$ & $\begin{array}{l}\text { Se plantea que el alumnado } \\
\text { reconozca contextos donde } \\
\text { la ciencia tiene un papel } \\
\text { relevante (salud, medio } \\
\text { ambiente, etc.) y donde se } \\
\text { puedan desarrollar acciones } \\
\text { que principalmente } \\
\text { promuevan habilidades } \\
\text { transversales como la } \\
\text { creatividad, el pensamiento } \\
\text { crítico, la colaboración o la } \\
\text { comunicación. }\end{array}$ & $\begin{array}{l}\text { Se pretende que el alumnado } \\
\text { disponga de conocimientos } \\
\text { científicos necesarios para } \\
\text { desarrollarse en la vida diaria, } \\
\text { resolver problemas y necesidades } \\
\text { básicas, en contextos donde la } \\
\text { ciencia tiene un papel relevante. } \\
\text { Se busca adquirir cultura científica } \\
\text { general a la vez que se desarrollan } \\
\text { habilidades transversales como la } \\
\text { creatividad, el pensamiento } \\
\text { crítico, la colaboración o la } \\
\text { comunicación. }\end{array}$ & $\begin{array}{l}\text { Se pretende que el alumnado se } \\
\text { vuelva competente } \\
\text { científicamente haciendo uso de } \\
\text { conocimiento científico que lo } \\
\text { capacite a tomar decisiones } \\
\text { argumentadas y actuar en un } \\
\text { ancho rango de situaciones, } \\
\text { movilizando capacidades } \\
\text { transversales como la } \\
\text { creatividad, el pensamiento } \\
\text { crítico, la colaboración o la } \\
\text { comunicación. }\end{array}$ & $\begin{array}{l}\text { Se pretende que el alumnado se vuelva } \\
\text { competente científicamente } \\
\text { involucrándolos en unas prácticas } \\
\text { científicas que los permitan construir y } \\
\text { dominar diversos modelos } \\
\text { científicos/ideas clave que los capaciten } \\
\text { en un ancho rango de situaciones, } \\
\text { movilizando capacidades transversales } \\
\text { como la creatividad, el pensamiento crítico, } \\
\text { la colaboración o la comunicación. }\end{array}$ \\
\hline & $\begin{array}{l}\text { Finalidades } \\
\text { didácticas }\end{array}$ & $\begin{array}{l}\text { Se pretende explorar un } \\
\text { contexto sin una finalidad } \\
\text { didáctica preestablecida. }\end{array}$ & $\begin{array}{l}\text { Se explora intencionalmente un } \\
\text { contexto para transferir } \\
\text { conocimientos construidos fuera } \\
\text { del marco del proyecto. } \\
\begin{array}{l}\text { Prevalece el pensamiento } \\
\text { concreto. }\end{array}\end{array}$ & $\begin{array}{l}\text { Se pretende hacer un uso } \\
\text { aplicado de los conocimientos } \\
\text { que aparecen en el proyecto. La } \\
\text { construcción de ideas más } \\
\text { abstractas se da en algunos } \\
\text { momentos del proyecto. }\end{array}$ & $\begin{array}{l}\text { Se pretende seguir un ciclo de aprendizaje } \\
\text { centrado en la construcción y aplicación } \\
\text { de conocimientos donde aparezcan } \\
\text { actividades secuenciadas progresivamente } \\
\text { hacia niveles más abstractos y que } \\
\text { finalmente se usen en nuevas situaciones } \\
\text { concretas. }\end{array}$ \\
\hline & $\begin{array}{l}\text { Reto del proyecto } \\
\text { (demanda) }\end{array}$ & $\begin{array}{l}\text { Se plantea un reto/pregunta } \\
\text { que promueve realizar tareas } \\
\text { principalmente reproductivas. } \\
\text { Aparecen pocas restricciones } \\
\text { que impliquen la necesidad } \\
\text { de comprender alguna } \\
\text { situación. }\end{array}$ & $\begin{array}{l}\text { Se plantea un reto/pregunta } \\
\text { provocativa y a largo plazo al } \\
\text { que se le puede dar respuesta sin } \\
\text { una necesidad clara de responder } \\
\text { a un objetivo de aprendizaje. }\end{array}$ & $\begin{array}{l}\text { Se plantea un reto/pregunta } \\
\text { provocativos, apropiado en } \\
\text { dificultad y que se resuelve a largo } \\
\text { plazo. Aparecen restricciones } \\
\text { que responden a algún objetivo } \\
\text { de aprendizaje. }\end{array}$ & $\begin{array}{l}\text { Se plantea un reto/pregunta provocativos, } \\
\text { apropiado en dificultad y que se resuelve a } \\
\text { largo plazo. Implica analizar y comprender } \\
\text { una situación para poder valorar y } \\
\text { argumentar la toma de decisiones (acción), } \\
\text { que responden a varios objetivos de } \\
\text { aprendizaje marcados. }\end{array}$ \\
\hline
\end{tabular}




\begin{tabular}{|c|c|c|c|c|c|}
\hline \multirow{4}{*}{ 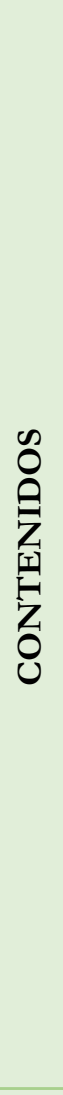 } & $\begin{array}{l}\text { Selección y } \\
\text { profundidad de } \\
\text { contenidos } \\
\text {-conceptuales }\end{array}$ & $\begin{array}{l}\text { Eventualmente, } \\
\text { incorporan } \\
\text { descriptivos en forma de } \\
\text { información o datos. Se } \\
\text { presentan } \\
\text { entre ellos. }\end{array}$ & $\begin{array}{l}\text { Se seleccionan contenidos que } \\
\text { permiten describir e identificar } \\
\text { fenómenos concretos que son } \\
\text { fácilmenter interpretables } \\
\text { (relaciones causa-efecto simples). }\end{array}$ & $\begin{array}{l}\text { Se seleccionan y organizan en } \\
\text { ideas clave que aparecen de } \\
\text { forma recurrente durante el } \\
\text { proyecto y que se desarrollan } \\
\text { de forma específica en ciertos } \\
\text { momentos del proyecto. }\end{array}$ & $\begin{array}{l}\text { Se seleccionan y organizan en ideas clave } \\
\text { que aparecen de forma recurrente y que se } \\
\text { desarrollan progresivamente a lo largo de } \\
\text { diferentes momentos para construir un } \\
\text { modelo teórico que permita explicar un } \\
\text { amplio rango de fenómenos. }\end{array}$ \\
\hline & $\begin{array}{l}\text { Selección y } \\
\text { profundidad de } \\
\text { contenidos } \\
\text {-procedimentales }\end{array}$ & $\begin{array}{llr}\text { Aparecen } & \text { descritos } \text { o se } \\
\text { entienden } & \text { como conocer } \\
\text { técnicas } & \text { concretas de } \\
\text { recogida y análisis de datos. } \\
\text { Éstos } & \text { se } & \text { trabajan } \\
\text { esporádicamente. }\end{array}$ & $\begin{array}{l}\text { Pueden aparecer expuestos de } \\
\text { forma descriptiva y se centran en } \\
\text { conocer las fases de una } \\
\text { investigación. }\end{array}$ & $\begin{array}{l}\text { Aparecen centrados en } \\
\text { conocer las fases de una } \\
\text { investigación haciendo énfasis } \\
\text { en alguna idea procedimental } \\
\text { más compleja como el control } \\
\text { de variables, el diseño } \\
\text { experimental, etc. }\end{array}$ & $\begin{array}{l}\text { Recurrentemente, aparecen } \\
\text { procedimientos complejos como el } \\
\text { diseño de experimentos, selección de } \\
\text { herramientas y estrategias adecuadas para } \\
\text { observar, recoger datos, interpretarlos, } \\
\text { seleccionar ciertos de validación de } \\
\text { resultados adecuados. }\end{array}$ \\
\hline & $\begin{array}{l}\text { Selección y } \\
\text { profundidad de } \\
\text { contenidos } \\
\text {-actitudinales }\end{array}$ & $\begin{array}{l}\text { Se plantea que se hagan } \\
\text { afirmaciones desligadas de } \\
\text { argumentos contrastados. } \\
\text { La motivación va asociada a } \\
\text { anécdotas o hechos } \\
\text { sorprendentes. }\end{array}$ & $\begin{array}{l}\text { Se promueve que se den } \\
\text { explicaciones a fenómenos que } \\
\text { aparecen sin necesidad de basarse } \\
\text { en pruebas. Aparecen actividades } \\
\text { que intentan despertar interés en } \\
\text { algún aspecto científico. }\end{array}$ & $\begin{array}{l}\text { Se promueve trabajar algunas } \\
\text { actitudes científicas como } \\
\text { basarse en pruebas para dar } \\
\text { explicaciones y generar } \\
\text { situaciones que creen un } \\
\text { interés sostenido en algún } \\
\text { aspecto científico. }\end{array}$ & $\begin{array}{l}\text { Se promueve trabajar tanto las actitudes } \\
\text { científicas como el rigor, objetividad o el } \\
\text { escepticismo, así como actitudes hacia la } \\
\text { ciencia (p. e. valorar el papel de la ciencia y } \\
\text { sus implicaciones). Se reflexiona sobre } \\
\text { valores relacionados con el conocimiento } \\
\text { desarrollado. }\end{array}$ \\
\hline & $\begin{array}{l}\text { Integración de } \\
\text { contenidos entre } \\
\text { asignaturas }\end{array}$ & $\begin{array}{l}\text { Se trabajan y relacionan } \\
\text { ideas cotidianas sobre el tema } \\
\text { tratado o se trabaja una única } \\
\text { asignatura. }\end{array}$ & $\begin{array}{l}\text { El contenido de diferentes } \\
\text { asignaturas se trabaja por } \\
\text { separado y hacen aportaciones } \\
\text { independientes en el proyecto. }\end{array}$ & $\begin{array}{l}\text { Los contenidos de diferentes } \\
\text { asignaturas se trabajan por } \\
\text { separado, pero se usan de forma } \\
\text { convergente en la producción } \\
\text { final. Puede aparecer una } \\
\text { asignatura central y otras que } \\
\text { hagan aportaciones. }\end{array}$ & $\begin{array}{l}\text { Los contenidos de diferentes asignaturas se } \\
\text { integran y contrastan durante todo el } \\
\text { proyecto. El proyecto supone trabajar } \\
\text { simultáneamente con las aportaciones } \\
\text { que puede hacer cada una. Suelen } \\
\text { integrarse } 2 \text { o } 3 \text { asignaturas con un peso } \\
\text { similar en el proyecto. }\end{array}$ \\
\hline & $\begin{array}{l}\text { Despliegue de la } \\
\text { acción }\end{array}$ & $\begin{array}{l}\text { Se explicita una propuesta } \\
\text { de acción. }\end{array}$ & $\begin{array}{l}\text { Se explicita una propuesta de } \\
\text { acción y se argumenta. }\end{array}$ & $\begin{array}{l}\text { Se explicita una propuesta } \\
\text { argumentada de acción, se } \\
\text { diseña y se pone en práctica. }\end{array}$ & $\begin{array}{l}\text { Se explicita una propuesta argumentada de } \\
\text { acción, se diseña, se pone en práctica, se } \\
\text { evalúa y se proponen mejoras. }\end{array}$ \\
\hline
\end{tabular}




\begin{tabular}{|c|c|c|c|c|c|}
\hline \multirow[b]{2}{*}{ Z } & $\begin{array}{l}\text { Ámbito de } \\
\text { realización e impacto } \\
\text { social }\end{array}$ & $\begin{array}{l}\text { La acción dirigida a la } \\
\text { propia clase. Los alumnos } \\
\text { son los beneficiarios del } \\
\text { proyecto, que repercute a } \\
\text { nivel personal. }\end{array}$ & $\begin{array}{l}\text { La acción dirigida a la } \\
\text { comunidad escolar (profesores, } \\
\text { alumnado de otros cursos, } \\
\text { trabajadores, etc.). El impacto } \\
\text { queda recluido en el recinto } \\
\text { escolar. }\end{array}$ & $\begin{array}{l}\text { La acción va dirigida a la } \\
\text { comunidad del entorno escolar } \\
\text { (padres, vecinos del barrio). El } \\
\text { impacto se asocia a un servicio } \\
\text { o actividad fuera del colegio. }\end{array}$ & $\begin{array}{l}\text { La acción va dirigida a una comunidad } \\
\text { social o profesional externa a la escuela o } \\
\text { el entorno escolar. Suele asociarse a un } \\
\text { encargo externo y genera un impacto } \\
\text { sostenido en ésta. }\end{array}$ \\
\hline & $\begin{array}{l}\text { Obertura de la } \\
\text { acción }\end{array}$ & $\begin{array}{l}\text { El proyecto está } \\
\text { completamente estructurado } \\
\text { y planificado en el tiempo } \\
\text { hacia un producto final } \\
\text { único y común sin margen } \\
\text { de decisión. }\end{array}$ & $\begin{array}{l}\text { El proyecto tiene una estructura } \\
\text { fija con un producto concreto } \\
\text { ligado a un reto planteado, pero } \\
\text { que permite algunos momentos } \\
\text { de libertad de decisión. }\end{array}$ & $\begin{array}{l}\text { El proyecto se presenta de } \\
\text { forma semiabierta, se plante un } \\
\text { reto ligado a un contexto } \\
\text { problemático donde los } \\
\text { alumnos han de escoger que } \\
\text { acción realizaran para superarlo. } \\
\text { Se admiten diferentes } \\
\text { producciones finales. }\end{array}$ & $\begin{array}{l}\text { El proyecto es completamente abierto y se } \\
\text { inicia de un contexto problemático donde } \\
\text { los alumnos identifican y escogen los retos } \\
\text { a los que quieren dar respuesta. Las formas } \\
\text { de abordar el reto se deciden y argumentan } \\
\text { por parte del alumno. }\end{array}$ \\
\hline \multirow[t]{2}{*}{ 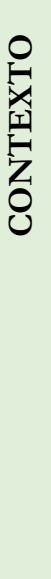 } & Relevancia & $\begin{array}{l}\text { Se plantean situaciones y } \\
\text { retos propuestos por el } \\
\text { alumno y que responden a } \\
\text { una curiosidad poco } \\
\text { sostenida en el tiempo. }\end{array}$ & $\begin{array}{l}\text { Se plantean situación y retos que } \\
\text { pueden surgir de los alumnos } \\
\text { pero que se conectan } \\
\text { puntualmente con posibles } \\
\text { intereses de éstos a nivel } \\
\text { individual, social o profesional. }\end{array}$ & $\begin{array}{l}\text { Se planean situaciones y retos } \\
\text { que conectan y generar } \\
\text { intereses a los alumnos a nivel: } \\
\text { individual, social i/o } \\
\text { profesional. }\end{array}$ & $\begin{array}{l}\text { Se planean situaciones y retos que } \\
\text { conectan y generar intereses (sostenidos } \\
\text { en el tiempo) a los alumnos a nivel: } \\
\text { individual, social i/o profesional. Se } \\
\text { intenta que estas situaciones generen } \\
\text { nuevos intereses e inquietudes más allá del } \\
\text { ámbito cotidiano. }\end{array}$ \\
\hline & $\begin{array}{l}\text { Significación } \\
\text { científica }\end{array}$ & $\begin{array}{l}\text { Se utiliza un contexto que } \\
\text { permiter conexiones } \\
\text { limitadas con el contenido } \\
\text { científico. }\end{array}$ & $\begin{array}{l}\text { Se utiliza un contexto donde se } \\
\text { identifican varios fenómenos que } \\
\text { permiten trabajar diferentes } \\
\text { ideas, aunque se explora con } \\
\text { preguntas que no lo reinterpretan. }\end{array}$ & $\begin{array}{l}\text { Se utiliza un contexto que } \\
\text { permite hacerse preguntas que } \\
\text { en algunos casos reinterpretan } \\
\text { algún fenómeno. El lenguaje } \\
\text { científicorere } \\
\text { progresivamente. aparece }\end{array}$ & $\begin{array}{l}\text { Se utiliza un contexto que permite hacerse } \\
\text { preguntas investigables científicamente. } \\
\text { Se reinterpretan fenómenos } \\
\text { incorporando nuevas formas de mirarlos } \\
\text { (desde diferentes disciplinas). El contexto } \\
\text { da sentido a los nuevos conceptos que se } \\
\text { asocian a un nuevo lenguaje. Ofrece una } \\
\text { imagen de cómo es la actividad científica. }\end{array}$ \\
\hline
\end{tabular}




\begin{tabular}{|c|c|c|c|c|c|}
\hline & Autenticidad & $\begin{array}{l}\text { Las situaciones y tareas que } \\
\text { se plantean pertenecen al } \\
\text { ámbito escolar, así como las } \\
\text { prácticas y las interacciones } \\
\text { que se establecen. }\end{array}$ & $\begin{array}{l}\text { Las situaciones y tareas que se } \\
\text { plantean son ficticias. Se recrean } \\
\text { situaciones simuladas pero que } \\
\text { plantean prácticas que se parecen } \\
\text { puntualmente a las del mundo } \\
\text { real. }\end{array}$ & $\begin{array}{l}\text { Las situaciones y tareas que se } \\
\text { plantean son verosímiles. Se } \\
\text { generan escenarios del mundo } \\
\text { real que se adaptan para poder } \\
\text { plantear prácticas más similares } \\
\text { al mundo real. }\end{array}$ & $\begin{array}{l}\text { Las situaciones y tareas que se plantean son } \\
\text { iguales (o muy similares) a las que suceden } \\
\text { en el mundo real (fuera de la escuela). Se } \\
\text { trabaja en situaciones ambiguas con } \\
\text { problemas no predefinidos que se } \\
\text { afrontan trabajando en grupo con } \\
\text { compañeros y/o personas externas al } \\
\text { centro. }\end{array}$ \\
\hline 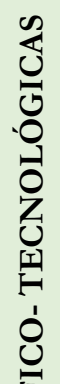 & $\begin{array}{l}\text { Participación en } \\
\text { prácticas científicas } \\
\text { - de argumentación } \\
\text { (evaluación de } \\
\text { pruebas y } \\
\text { construcción de } \\
\text { argumentos) }\end{array}$ & $\begin{array}{l}\text { Existen pocos espacios de } \\
\text { argumentación o se limitan } \\
\text { a comunicar resultados de } \\
\text { manera descriptiva. }\end{array}$ & $\begin{array}{l}\text { Se promueve alguna actividad de } \\
\text { argumentación, pero no siempre } \\
\text { está relacionada con una } \\
\text { argumentación científica basada } \\
\text { en pruebas. }\end{array}$ & $\begin{array}{l}\text { Se promueve que se } \\
\text { argumente científicamente en } \\
\text { ciertos momentos del proyecto. } \\
\text { Aparecen herramientas de } \\
\text { soporte del discurso para que } \\
\text { se basen en pruebas y se } \\
\text { promueva pensar en un } \\
\text { modelo concreto. }\end{array}$ & $\begin{array}{l}\text { Se centra en trabajar la argumentación } \\
\text { científica. Aparece de forma recurrente } \\
\text { durante el proyecto y se sofistica a través } \\
\text { de este. La argumentación se convierte en } \\
\text { una herramienta para establecer diálogo entre } \\
\text { el fenómeno que se indaga y el modelo } \\
\text { que se construye, así como para contrastar } \\
\text { modelos entre alumnos. También se } \\
\text { argumentan las decisiones que se toman } \\
\text { durante el proyecto. }\end{array}$ \\
\hline 当 & $\begin{array}{l}\text { Participación en } \\
\text { prácticas científicas } \\
\text { - de indagación } \\
\text { (recogida y análisis } \\
\text { de datos } \\
\text { provenientes de } \\
\text { observaciones o } \\
\text { experimentos) }\end{array}$ & $\begin{array}{l}\text { Se plantean pocas preguntas } \\
\text { que sean científicas o } \\
\text { investigables científicamente. } \\
\text { La investigación se entiende } \\
\text { como la recogida y síntesis } \\
\text { de información. }\end{array}$ & $\begin{array}{l}\text { Se plantean preguntas científicas } \\
\text { que se responden parcialmente } \\
\text { con una actividad indagativa. } \\
\text { La parte experimental o de } \\
\text { campo es esporádica y busca que } \\
\text { los alumnos conozcan la } \\
\text { situación que se está trabajando } \\
\text { más que transformar su visión de } \\
\text { esta. }\end{array}$ & $\begin{array}{l}\text { Se plantean preguntas } \\
\text { científicamente orientadas y que } \\
\text { promueven planificar } \\
\text { investigaciones para } \\
\text { observar y recoger pruebas } \\
\text { que las respondan. Se pide que } \\
\text { se extraigan conclusiones y se } \\
\text { desarrollen explicaciones. El } \\
\text { trabajo experimental o de } \\
\text { campo predomina en algunos } \\
\text { momentos del proyecto. }\end{array}$ & $\begin{array}{l}\text { Se plantean preguntas científicamente } \\
\text { orientadas y que promuevan planifica } \\
\text { investigaciones para observar y recoger } \\
\text { pruebas que las respondan. Se pide que se } \\
\text { extraigan conclusiones y se desarrollen } \\
\text { explicaciones, así como que se evalúen a } \\
\text { partir del conocimiento científico } \\
\text { adquirido. El trabajo de campo o } \\
\text { experimental predomina a lo largo del } \\
\text { proyecto. }\end{array}$ \\
\hline
\end{tabular}




\begin{tabular}{|c|c|c|c|c|c|}
\hline & $\begin{array}{l}\text { Participación en } \\
\text { prácticas científicas } \\
\text { - de modelización } \\
\text { (construcción de } \\
\text { teorías y modelos) }\end{array}$ & $\begin{array}{l}\text { Los conceptos abstractos se } \\
\text { presentan descriptivamente, } \\
\text { las actividades que aparecen } \\
\text { buscan aplicar aquellos } \\
\text { conceptos que se necesitan y } \\
\text { no aparece un proceso } \\
\text { concreto que persiga } \\
\text { comprender un concepto } \\
\text { complejo. }\end{array}$ & $\begin{array}{l}\text { Aparecen algunas actividades } \\
\text { destinadas a trabajar } \\
\text { puntualmente algunos conceptos } \\
\text { científicos más complejos que } \\
\text { resultan necesarios en algún punto } \\
\text { del proyecto. }\end{array}$ & $\begin{array}{l}\text { Aparecen actividades que } \\
\text { promueven profundizar en } \\
\text { algún modelo científico, } \\
\text { visitando algunas de sus ideas } \\
\text { clave. Se intenta dar explicación } \\
\text { a fenómenos estrechamente } \\
\text { ligados a la acción. }\end{array}$ & $\begin{array}{l}\text { Se promueve la comprensión de un modelo } \\
\text { teórico que se construye de forma } \\
\text { secuencial introduciendo ideas que se } \\
\text { contrasten con los modelos previos. } \\
\text { Aparecen preguntas que promueven } \\
\text { imaginar el mecanismo que explica un } \\
\text { fenómeno y revisar el modelo. Pare del } \\
\text { reto del proyecto consiste en implicar-se } \\
\text { en este proceso de desarrollo y uso del } \\
\text { modelo. }\end{array}$ \\
\hline & $\begin{array}{l}\text { Participación en } \\
\text { prácticas } \\
\text { tecnológicas }\end{array}$ & $\begin{array}{l}\text { Se realiza un proceso de } \\
\text { construcción siguiendo un } \\
\text { protocolo para generar un } \\
\text { producto final. }\end{array}$ & $\begin{array}{l}\text { Se plantea dar respuesta a un } \\
\text { problema planteado siguiendo un } \\
\text { proceso de construir y testar un } \\
\text { producto. }\end{array}$ & $\begin{array}{l}\text { Se plantea dar respuesta a un } \\
\text { problema ideando una } \\
\text { solución prototipando y } \\
\text { testando un producto. }\end{array}$ & $\begin{array}{l}\text { Se plantea involucrarse en prácticas como } \\
\text { empatizar con una comunidad, definir un } \\
\text { problema, idear una solución y testarla } \\
\text { para así movilizar unos contenidos y } \\
\text { construir un producto que responda a las } \\
\text { necesidades identificadas. }\end{array}$ \\
\hline & Recursos TIC & $\begin{array}{l}\text { Aparecen escasos recursos } \\
\text { TIC o se hace un uso } \\
\text { esporádico. }\end{array}$ & $\begin{array}{l}\text { Se incorpora la presentación de } \\
\text { algunas herramientas y recursos } \\
\text { TIC. Pueden aparecer algunas } \\
\text { actividades de asociación de } \\
\text { elementos. }\end{array}$ & $\begin{array}{l}\text { Se incorpora el uso de } \\
\text { herramientas y recursos TIC en } \\
\text { algunos momentos, } \\
\text { profundizando en algunas } \\
\text { ventajas que ofrecen. Se } \\
\text { pueden incorporar software } \\
\text { para representar y organizar } \\
\text { ideas. }\end{array}$ & $\begin{array}{l}\text { Se incorpora el uso de herramientas y } \\
\text { recursos de forma recurrente con un } \\
\text { claro enfoque didáctico: ayudan a pensar } \\
\text { y a facilitar la organización, construcción } \\
\text { y comunicación de ideas. Se reflexiona } \\
\text { sobre otros usos fuera del contexto en } \\
\text { las que se usan y pueden aparecer } \\
\text { animaciones y simulaciones. }\end{array}$ \\
\hline Z & $\begin{array}{l}\text { Evaluación del } \\
\text { proceso }\end{array}$ & $\begin{array}{l}\text { Aparecen escasos momentos } \\
\text { de revisión de lo que se } \\
\text { aprende, en los cuales el } \\
\text { profesor asume el rol de } \\
\text { detectar errores, analizarlos y } \\
\text { hacer propuestas para } \\
\text { mejorarlos. El rol del } \\
\text { alumnado es revisar en casa } \\
\text { su trabajo en función de la } \\
\text { revisión. }\end{array}$ & $\begin{array}{l}\text { El profesorado evalúa cada tarea } \\
\text { y en relación con alguna de estas, } \\
\text { pide al alumnado que se co-evalúe } \\
\text { para detectar dificultados y hacer } \\
\text { propuestas de mejora a partir de } \\
\text { criterios dados una vez hecha la } \\
\text { tarea y que aplican para hacer } \\
\text { revisión. }\end{array}$ & $\begin{array}{l}\text { Al inicio se comunican los } \\
\text { objetaos del proyecto y a lo } \\
\text { largo de él se discuten como } \\
\text { planificar la realización de } \\
\text { algunas tareas y criterios para } \\
\text { evaluar su calidad. Se } \\
\text { promueve que los alumnos lo } \\
\text { tengan en cuenta al realizarlas. }\end{array}$ & $\begin{array}{l}\text { Se discute con el alumnado los objetivos } \\
\text { del proyecto a medida que les pueden } \\
\text { aparecer, cómo planificar la realización de } \\
\text { algunas tareas clave (transferibles), así } \\
\text { como los criterios para evaluar su calidad. } \\
\text { Se prevé un tiempo para aplicar dichos } \\
\text { criterios a la co- y autoevaluación, vista } \\
\text { como regulación de las dificultades que } \\
\text { vayan emergiendo }\end{array}$ \\
\hline
\end{tabular}




\begin{tabular}{|c|c|c|c|c|c|}
\hline & $\begin{array}{l}\text { Evaluación del } \\
\text { resultado }\end{array}$ & $\begin{array}{l}\text { Se identifican unas tareas que } \\
\text { se tendrán en cuenta para } \\
\text { cualificar (una es el producto } \\
\text { final) y se hace una } \\
\text { ponderación entre todas. Se } \\
\text { continúa pensando en clave } \\
\text { de asignatura. }\end{array}$ & $\begin{array}{l}\text { De las tareas seleccionadas, } \\
\text { alguna se utiliza para que el } \\
\text { alumnado se co- } \quad \text { o } \\
\text { autoevalúe/cualifique a partir de } \\
\text { listas de criterios o rúbricas dadas } \\
\text { por el profesorado. La } \\
\text { cualificación sale de la } \\
\text { ponderación de las calificaciones } \\
\text { y el producto final tiene un valor } \\
\text { importante. Se continúa pensando } \\
\text { en clave de asignatura. }\end{array}$ & $\begin{array}{l}\text { Los criterios consensuados } \\
\text { con el alumnado se usan para } \\
\text { evaluar la calidad de las tareas } \\
\text { realizadas. Su punto de vista } \\
\text { se triangula con el de } \\
\text { compañeros y profesorado. Se } \\
\text { pide que piensen más en lo } \\
\text { que han aprendido desde el } \\
\text { inicio que no en el producto } \\
\text { final. Se evalúa por } \\
\text { asignaturas, aunque se } \\
\text { consideran aspectos } \\
\text { transversales. }\end{array}$ & $\begin{array}{l}\text { A partir de los objetivos competenciales } \\
\text { del proyecto, se consensuan unos criterios } \\
\text { o rúbricas y se promueve que el alumnado } \\
\text { encuentre evidencias de su trabajo que } \\
\text { posibilite deducir el nivel alcanzado. Se } \\
\text { triangulan los puntos de vista y, respecto } \\
\text { al producto final, se valora especialmente la } \\
\text { reflexión crítica sobre qué se podría } \\
\text { mejorar. Se evalúa considerando las } \\
\text { competencias específicas y transversales } \\
\text { del currículo. }\end{array}$ \\
\hline 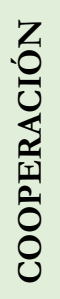 & $\begin{array}{l}\text { Regulación del } \\
\text { trabajo cooperativo }\end{array}$ & $\begin{array}{l}\text { Aparecen actividades } \\
\text { individuales que se realizan } \\
\text { en grupo, la regulación del } \\
\text { trabajo en grupo es limitada. }\end{array}$ & $\begin{array}{l}\text { Aparecen equipos de trabajo que } \\
\text { se regulan por la asignación de } \\
\text { roles fija. La regulación del } \\
\text { trabajo en grupo es limitada. }\end{array}$ & $\begin{array}{l}\text { Aparece alguna estrategia para } \\
\text { regular el trabajo en grupo } \\
\text { como rúbricas, diarios i/o } \\
\text { compromisos de equipo. El } \\
\text { alumnado tiene asignados } \\
\text { roles dentro del grupo. }\end{array}$ & $\begin{array}{l}\text { Aparecen diferentes estrategias de } \\
\text { regulación del trabajo en grupo como } \\
\text { rúbricas, diarios y/o compromisos de } \\
\text { equipo, etc. que valoran la implicación y } \\
\text { participación en el proyecto. El alumnado } \\
\text { tiene asignado roles dentro del grupo. El } \\
\text { trabajo en grupo resulta importante al } \\
\text { estructurar nuevas ideas. }\end{array}$ \\
\hline
\end{tabular}

